\title{
Molecular Geometry in Polymerization Formation
}

\author{
Wesley Bruski Barbero \\ Medical Student, Harvard Medical School
}

\section{A R}

Article history:

Received 27 March 2021

Accepted 08 March 2021

Revised 12 March 2021

Available online 18 March 2021

Keywords:

Polymerization

matrix determinants

Polymers

\begin{abstract}
A $\quad$ B $\quad S \quad T \quad R \quad A \quad C \quad T$
The crosslinking agent used to obtain a MIP (Molecularly Printed Polymer) performs the following three main functions: control of the morphology of the polymeric matrix (gel-like polymer, macroporous polymer or microgel powder); stabilization of binding sites capable of molecular recognition; mechanical stabilization of the polymeric matrix. Proposal: Molecular modeling observing a polymerizable scale factor in $\mathrm{k}$ set of functional monomers using the cross-linking agent tetra-methylene-dimethacrylate. Where the equation is: $\mathrm{k}$. $(\mathrm{K}-\mathrm{n})=\mathrm{Rt}^{1}-\mathrm{Rt} \mathrm{t}^{2} / \mathrm{Rr}$ It is explained that $\mathrm{k}$ is the subset of parameters obtained in distribution of probability density between the $A B$ interval, with the total number of events possible being equal to the solvent ratio that occurs in $\mathrm{T} 1$ initial time and $\mathrm{T} 2$ time interval to be measured divided by the ratio crosslinking. Diffusion coefficient of chemical species: $\mathrm{k}^{1}$. (Kn - plim $\left.\infty\right)$ $=\mathrm{DX}+\mathrm{DY}+\mathrm{DZ}$ where $\mathrm{k}^{1}$ which is the initial coefficient of molar ratio / kinetic ratio multiplied by $\mathrm{kn}$ which is the exponential critical exponent of renormalized reactivity decreased by progression critical kinetic limit equal to the correlation to the three-dimensional chemical crossing matrix determinants in $\mathrm{X}, \mathrm{Y}$ and $\mathrm{Z}$.
\end{abstract}

(C) 2021, Barbero WB. This is an open-access article distributed under the terms of the Creative Commons Attribution 4.0 International License, which permits unrestricted use, distribution and reproduction in any medium, provided the original author and source are credited

\section{Introduction}

The crosslinking agent used to obtain a MIP (Molecularly Printed Polymer) performs the following three main functions: control of the morphology of the polymeric matrix (gel-like polymer, macroporous polymer or microgel powder); stabilization of binding sites capable of molecular recognition; mechanical stabilization of the polymeric matrix.

Proposal: Molecular modeling observing a polymerizable scale factor in $\mathrm{k}$ set of functional monomers using the cross-linking agent tetra-methylene-dimethacrylate. Where the equation is: $\mathrm{k} .(\mathrm{K}-\mathrm{n})=\mathrm{Rt}^{1}-\mathrm{Rt}^{2}$ $/ \mathrm{Rr}$

It is explained that $\mathrm{k}$ is the subset of parameters obtained in distribution of probability density between the $A B$ interval, with the total number of events possible being equal to the solvent ratio that occurs in $\mathrm{T} 1$ initial time and $\mathrm{T} 2$ time interval to be measured divided by the ratio crosslinking.

Diffusion coefficient of chemical species: $\mathrm{k}^{1} \cdot(\mathrm{Kn}-$ plim $\infty)=\mathrm{DX}+$ $\mathrm{DY}+\mathrm{DZ}$ where $\mathrm{k}^{1}$ which is the initial coefficient of molar ratio/kinetic ratio multiplied by $\mathrm{kn}$ which is the exponential critical exponent of renormalized reactivity decreased by progression critical kinetic limit equal to the correlation to the three-dimensional chemical crossing matrix determinants in $\mathrm{X}, \mathrm{Y}$ and $\mathrm{Z}$.

* Corresponding author

Wesley Bruski Barbero, Pharm Medical Student, Harvard

Medical School

Mobile: 55-49-98418-8853

E-mail address: wb-barbero@uol.com.br
Homogeneous or heterogeneous catalysis of single atom organic metals, covalence, kinetics, complex burger system, coupling of aromatic azo-aromatic compounds, organometallic compounds, nucleophilic attack to spatial structure, possibility of efficient catalyst that integrates homogeneous and heterogeneous processes by transition metals coupled to spatial chains, selectivity of catalysis by Pt platinum which is a transition metal, the oxygen waves act as Lewis acids - possibility: A Lewis acid is a chemical species in which one of its constituent atoms has electron deficiency. This column makes it susceptible to accept an electron pair, and therefore to create a coordinated covalent bond with a Lewis base. In which isolated and positively charged metal centers can successfully suppress the adsorption of $\mathrm{C}=\mathrm{C}$ bonds, which would easily occur in their nanoparticle counterparts.

Reaction distribution of acid and solvents Dtma/Dtre $=$ Dtms/Dtcs which means acid molar ratio determinant divided by Lewis acid electron exchange determinant equal to the solvent molar ratio determinant divided by the solvent kinetic ratio determinant.

For the creation of Molecularly Printed Polymers in the improvement of high performance catalytic agents, the following solution is adopted:

First of calculating through the Graph Theory the stability index of most graphs, looking at vertices and edges together, for synthesis of nucleophilic attack, then we have:

The stability index of almost every graph is surprisingly low compared to the number of vertices in the graph:

However small the positive number $\varepsilon$, we have $\alpha(G)<(2+\varepsilon) \log 2 n$ 
for almost every graph $\mathrm{G}$ in $\mathrm{G}(\mathrm{n})$. PROOF: Let $\mathrm{k}$ be the number $\mathrm{d}(2+\varepsilon)$ $\log 2$ ne and denote by $Q(n, k)$ the set of $k$ graphs in $G(n)$ for which $\alpha \geq$ $\mathrm{k}$. It remains to show that $\lim \mathrm{n} \rightarrow \infty|\mathrm{Q}(\mathrm{n}, \mathrm{k})||\mathrm{G}(\mathrm{n})|=0$. (2.1) Let $X$ be a subset of $\mathrm{V}$ with $\mathrm{k}$ elements. There is a one-to-one correspondence between the graphs in $G(n)$ in which $X$ is stable and the subsets of $V$ (2) $\mathrm{rX}(2)$. Therefore, $\mathrm{X}$ is stable at $2 \mathrm{~N}-\mathrm{K}$ of the graphs, where $\mathrm{K}:=$ $\mathrm{k} 2$. Since $\mathrm{V}$ has $\mathrm{k} \leq \mathrm{nkK}$ subsets of cardinality $\mathrm{k}$, we have $|\mathrm{Q}(\mathrm{n}, \mathrm{k})| \leq$ nk $2 \mathrm{~N}-\mathrm{K}$, and therefore $|\mathrm{Q}(\mathrm{n}, \mathrm{k})||\mathrm{G}(\mathrm{n})| \leq \mathrm{nk} 2-\mathrm{k}(\mathrm{k}-1) / 2$. It follows that $2 \log 2(|\mathrm{Q}(\mathrm{n}, \mathrm{k})| /|\mathrm{G}(\mathrm{n})|) \leq 2 \mathrm{k} \log 2 \mathrm{n}-\mathrm{k}(\mathrm{k}-1)=\mathrm{k}$ $(1+2 \log 2 n-k) \leq d(2+\varepsilon) \log 2-n e(1+2 \log 2 n-(2+\varepsilon) \log 2 n)=$ $d(2+\varepsilon) \log 2$ ne $(1-\varepsilon \log 2 n) .(2.2)$

Since $\operatorname{limn} \rightarrow \infty(1-\varepsilon \log 2 \mathrm{n})=-\infty$, we have $\lim \mathrm{n} \rightarrow \infty$

$\log 2|\mathrm{Q}(\mathrm{n}, \mathrm{k})||\mathrm{G}(\mathrm{n})|=-\infty$, and that proves (2.1). For example, if $\varepsilon=0.2$ then, by virtue of (2.2), we have $|\mathrm{Q}(1024.22)| \leq 2220-231$ $|\mathrm{G}(1024)|$ and therefore a fraction of at least 1-2-11 (more than 99.9\%) of the graphs in $\mathrm{G}(1024)$ have $\alpha<22$, mainly in the occurrence of spatial determination of exchange of electron pairs.

In addition, we need to worry about the rotation part of an integral. Jij $\Psi \mathrm{ij} \mathrm{Jij} \mathrm{-} \mathrm{K} \mathrm{eij.}==\mathrm{R} 12$.

Note that 1 / rij does not depend on any rotation coordinates. This means that all elements of the 1 / rij matrix must be diagonal in the rotation $(\alpha / \beta)$ of the electrons $i$ and $j$. For 2 electrons $222 \mathrm{~J}$ and $1 \mathrm{~s}=$ $\mathrm{J} 1 \mathrm{~s} \mathrm{~K}$ e1s $=0$ eJ $1 \mathrm{~s} \alpha, 2 \mathrm{~s} \alpha=\mathrm{J} 1 \mathrm{~s}, 2 \mathrm{~s} \mathrm{~K} 1 \mathrm{~s} \alpha, 2 \mathrm{~s} \alpha=\mathrm{K} 1 \mathrm{~s}, 2 \mathrm{~s}$ ee J1s $\alpha, 2 \mathrm{~s} \beta=$ $\mathrm{J} 1 \mathrm{~s}, 2 \mathrm{~s} \mathrm{~K} 1 \mathrm{~s} \alpha, 2 \mathrm{~s} \beta=0$. If, instead, we look explicitly at the $\alpha \beta+\beta \alpha$ and $\alpha \beta-\beta$ generate their own states, we want $2-1 / 2$ [s $1 \mathrm{~s} \alpha, 2 \mathrm{~s} \beta \pm \Psi 1 \mathrm{~s} \beta$, $2 \mathrm{~s} \alpha] 1[\Psi 1 \mathrm{~s} \alpha, 2 \mathrm{~s} \beta \pm \Psi 1 \mathrm{~s} \beta, 2 \mathrm{~s} \alpha] \mathrm{r} 12$ from which we obtain 11 (J1s $2 \mathrm{~s}+$ $J 1 s 2 s)(K 1 s 2 s+K 1 s 2 s)=J 1 s 2 s$ K1s2s. 2 of the diagonal of the transverse terms 6 terms note that this inversion of the signal comes from the permutation of 1-2 electrons The upper signal corresponds to the triplet E3s $=J 1 \mathrm{~s}, 2 \mathrm{~s}-\mathrm{K} 1 \mathrm{~s}, 2 \mathrm{~s} E 1 \mathrm{~s}=\mathrm{J} 1 \mathrm{~s}, 2 \mathrm{~s}+\mathrm{K} 1 \mathrm{~s}, 2 \mathrm{~s}$.

Calculate the probability density of Bayesian electron statistics: Probability Density In tatistics, the probability density distribution is a function used to represent the probability distribution of a continuous random variable. Uses the calculation: $f(x)=S a b f(x) d x$

Then the systems calculation described by a Hamiltonian is made, calculating the scale factor that reduces the freedom of the atom's dimensional system.

The trajectory integral must be calculated, which consists of a superposition of local harmonic oscillator trajectory integrals centered on average positions (x0), each with its own frequency $\Omega(\mathrm{x} 0)$.

Finally, the Slater determinants are used to calculate the energies. In addition to calculating for the spin connection of the paired electrons in opposite directions, the electron rotation orbitals and the determination of space orbitals, so to speak the esterification reactions are accelerated by the presence of $\mathrm{H}+$ ions, so one can to establish the formation of diagrams and computational modeling of a Molecularly Printed Polymer through the creation of a spatial modeling algorithm, in view of the library of polymers and chemical affinities, creating a complex system of graphic determinants of vertices and edges for molecular geometry. There was a discovery that the stability index of almost all graphs is low compared to the number of vertices in the graph.

\section{Conflict Of Interest}

None

Acknowledgements

None

\section{References}

1. Albeverio S, Hoegh-Krohn R. A Remark on the Connection Batween Stochastic Jl.1echanics and the Heat Equation. J Phys. 1974;15(10): 1745 .

2. Aguirre, Luiz Antonio. Introdução À Identificação de Sistemas . Minas Gerais: UFMG, 2007.

3. Ballentine, L.S. The Statistical Interpretation of Quantum Mechanics. Rev Mod Phys. 1970;42:358.

4. Boldrini, José Luiz. Álgebra linear. São Paulo: Harba, 1980.
5. Bohm, D. Causality and Chance in Modern Physics. Routledge \& Kegan Paul, LTD. 1967.

6. Carmen Lys Ribeiro Braga. Notas de Física-Matemática: Equações Diferenciais, Funções de Green e Distribuições. Editores: Walter F. Wreszinski, Jose F. Perez, Domingos H. U. Marchetti e João C. A. Barata. Ed. Livraria da Física, São Paulo. 1a edição, 2006.

7. C.H. Bennett. Logical reversibility of computation. IBM Journal of Research and Development. 1973;17:525.

8. Curso de Física-Matemática, J.C.A. Barata, http://denebola.if.usp. br/ jbarata/Notas_de_aula/ Capítulo 16, Capítulo 19, Capítulo 36, Capítulo 37, Capítulo 38.

9. David J. Griffits, Mecânica quântica, ed. 2, tradução Lara freitas, (Pearson, São Paulo).

10. Díaz, J. L. F. Geração de emaranhamento de polarização entre pares de fótons no regimede femtossegundos.Dissertação (Mestrado)Universidade Federalde Pernambuco. 2014.

11. D. Deutsch, R. Jozsa. Rapid solution of problems by quantum computation. Proceedings of the Royal Society A. 1992;43:553.

12. FAS. Barbosa, AS. Coelho, KN. Cassemiro, P. Nussenzveig, C. Fabre, M. Martinelli, AS. Villar. Beyond spectral homodyne detection: Complete quantum measurement of spectral modes of light. Physical Review Letters. 2013;111:200402.

13. Hänsch, TW, Schawlow A.L. Cooling of gases by laser radiation. Opt Commun. 1975;13:1.

14. H Jeffreys. Theory of Probability (Oxford University Press, 1998).

15. Kobayashi K, Ohtsuki, T, Slevin K. Critical exponent for the quantum spin Hall transition in Z2 Network Model. Phys Rev B, 2011;1:1-5.

16. Kok, P. et al. Linear optical quantum computing with photonic qubits. Rev. Mod. Phys., v. 79, n. 1, 2007.

17. Mandelbrot, Benoit B. The Fractal Geometry of Nature. New York: W. H. Freeman and Company, 1977.

18. Reed M., Simon B. M.O. Scully, M.S. Zubairy. Methods of Modern Mathematical Physics Vol. 1-4, Quantum Optics (Cambridge University Press, 1997).

19. Parisio, F. Estimating the reduction time of quantum states. Phys Rev A. 2011;84(6).

20. R. Cleve, A. Ekert, C. Macchiavello, M. Mosca. Quantum algorithms revisited. Proceedings of the Royal Society A. 1998;454:339.

21. Stewart, James. Antonio Carlos Moretti. Cálculo, volume 1. São Paulo: Cengage Learning, 2012.

22. Varriale, M. C. Transição de localização em potenciais aleatórios com correlações de longo alcance,. Tese (Doutorado) - UFRGS, Porto Alegre, (1994).

23. Wegner, F. Electrons in disordered systems. Scaling near the mobility edge Zeits. Phys B Condens Matt. 1976;25(4)327-337.

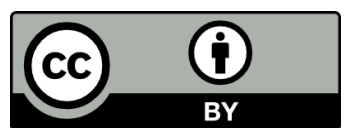

